\title{
Direitos territoriais indígenas às sombras do passado
} Indigenous peoples lands rights under the shadow of the past

\section{Carolina Ribeiro Santana ${ }^{1}$}

1 Universidade de Brasília, Brasília, Distrito Federal, Brasil. E-mail: kkrsantana@gmail.com. ORCID: https://orcid.org/0000-0003-0362-0830.

\section{Thiago Mota Cardoso ${ }^{2}$}

2 Universidade Federal da Bahia, Salvador, Bahia, Brasil. E-mail: thiagotxai@gmail.com. ORCID: http://orcid.org/0000-0002-7220-7487.

Artigo recebido em 18/03/2019 e aceito em 20/06/2019.

\section{$(\mathrm{cc}) \mathrm{EY}$}

This work is licensed under a Creative Commons Attribution 4.0 International License 


\section{Resumo}

O presente artigo parte da análise dos Anais da Assembleia Constituinte de 1987/88 para compreender a elaboração das garantias territoriais indígenas. Demonstramos que parlamentares e juristas da atualidade estão retomando os exatos termos dos debates realizados para reavaliar tais direitos diante de casos concretos e específicos.

Palavras-chave: Assembleia constituinte; Povos indígenas; Demarcação de terras.

\section{Abstract}

This paper is guided by the legislative process of the constitutional making of the indigenous lands rights during the Brazil's Constituent Assembly of 1987/88. The analysis of the process shows that parliamentarians and jurists of nowadays are taking up the exact terms of the discussions that happened revaluate these rights in the face of specific and concrete cases.

Keywords: Constituent assembly; Indigenous peoples; Lands demarcation. 


\section{Considerações iniciais}

Recentemente, o fotógrafo Sebastião Salgado inaugurou no Hall dos Bustos do Supremo Tribunal Federal uma exposição que retrata indígenas de recente contato da etnia Korubo, habitante da Amazônia. No discurso de abertura Salgado afirmou que "essas populações indígenas representam a pré-história da humanidade, feliz o país como o nosso que pode conviver com sua pré-história", e completou afirmando que eles "vivem como nós vivíamos há 4 mil anos atrás, num estado de natureza fenomenal"1.

Aparentemente inocente, a frase carrega um conhecido equívoco. Proferida no palco da recente desconstrução dos direitos territoriais dos povos indígenas, a Suprema Corte $^{2}$, revela não apenas seu etnocentrismo, mas enrobustece o discurso da negação do presente às populações indígenas. Este estereótipo de povos do passado produz um curioso fenômeno na opinião de grande parte da população brasileira, a dificuldade de aceitação de que eles tenham direitos no presente, e mais, engendra a reiterada retomada de debates já exaustivamente travados durante a Assembleia Nacional Constituinte de $87 / 88$. Para o senso comum, e nisso incluem-se parlamentares e juristas, teriam quais direitos ao presente ou ao futuro povos que, supostamente, sequer teriam saído do passado?

Para compreender esse insistente retorno dos debates constituintes é preciso, antes, retornarmos a eles e inteirarmo-nos do que pensavam os atores que na Assembleia discutiram a elaboração do texto do artigo 231.

O processo de elaboração do artigo 231

Em fevereiro de 1987 instalava-se no país a Assembleia Nacional Constituinte e, com ela, a esperança por dias melhores e pelo resgate de direitos autoritariamente violados durante o regime ditatorial. A expectativa, todavia, já vinha do momento préconstituinte $^{2}$ que agitou não apenas movimentos sociais urbanos e campesinos, mas

\footnotetext{
1 BRASIL. Supremo Tribunal Federal. STF expõe obras da mostra "Amazônia", do fotógrafo Sebastião Salgado. Disponível em: http://www.stf.jus.br/portal/cms/verNoticiaDetalhe.asp?idConteudo=370022. Consulta em 02 de ago. 18.

${ }^{2}$ Sobre a descaracterização dos direitos constitucionais indígenas pelo judiciário ver SANTANA, Carolina R. Direitos territoriais indígenas: o STF contra a Constituição. In: ALCÂNTARA, Gustavo K., MAIA, Luciano M., TINÔCO, Lívia N. (Org.) Índios, direitos originários e territorialidade. Brasília: Editora ANPR, 2018, p. 451 479. Disponível em: http://anpr.org.br/assets/uploads/files/publicacoes/i\%20-\%20j/indiosPDF.pdf
} 
alcançou também o grupo que vinha tomando forma juntamente com o ritmo das lutas democráticas: o movimento indígena ${ }^{3}$. A participação deste e dos demais setores populares organizados em movimentos sociais foi, como lembrou Marilena Chauí, fundamental para o resgate do anseio da transformação política, histórica e cultural que se desejava como resultado (CHAUI, 1987).

Para a antropóloga Manuela Carneiro da Cunha, figura atuante durante o processo constituinte (CUNHA, 2018) - à época presidente da Associação Brasileira de Antropologia - a revogação do projeto histórico empreendido pelo Estado brasileiro de assimilação dos indígenas à sociedade nacional é uma das grandes conquistas dos povos indígenas. O jurista Carlos Frederico Marés de Souza Júnior, também atuante durante o processo constituinte ${ }^{4}$, relata-nos que em meados de 1988, em um diálogo com um indígena Macuxi a respeito do significado da constituição, deu-se conta de que por melhor que fosse, uma Constituição não passaria "de uma coisa de branco, de uma forma de expressão de um direito que continuava sendo de dominador". O indígena Ailton Krenak, que proferiu antológico discurso durante a constituinte, afirma que para os indígenas a ocasião significou uma experiência de redescobrir o país. Segundo ele "depois de escapar do genocídio, os índios descobriram o Brasil na luta pelo direito de estar presente aqui" (KRENAK, 2018).

Mobilizados, em grande parte, pelo Conselho Indigenista Missionário - CIMI e também pela União das Nações Indígenas - UNI, mais do que readquirir direitos atropelados pela ditadura, as lideranças indígenas deslocaram-se para Brasília no intuito de reivindicar suas condições existenciais, visceralmente atreladas ao seu direito de permanecer em suas terras. Com isto não queremos afirmar que os indígenas não tiveram direitos violados pela ditadura, mas, antes, que sequer seus direitos mais primordiais eram garantidos pelo Estado ${ }^{5}$. Até o momento da Constituinte um número

\footnotetext{
${ }^{3}$ Visando impedir que o projeto de redemocratização do Brasil fosse sobrepujado pela ideia de conservação e assumisse linhas indesejadas de continuidade como autoritarismo, em seguida à eleição de Tancredo e Sarney, novos movimentos sociais passaram a ser organizados por todo o país (VERSIANI, 2014, p.369).

${ }^{4}$ Assessorou, juntamente com Dalmo Dallari, diversas entidades consultadas pelo constitucionalista José Afonso da Silva a respeito do texto acerca dos direitos indígenas elaborado na comissão Afonso Arinos (Sobre a comissão ver nota 11). Entre as entidades estavam a Comissão Pro-Índio de São Paulo, a Associação Nacional de Apoio ao Índio do Rio Grande do Sul (ANAí - RS), o Centro de Trabalho Indigenista (CTI), a Associação Brasileira de Antropologia (ABA), a UNI- Sul, a Coordenação de Terras Indígenas do Ministério da Reforma e do Desenvolvimento Agrário (Mirad), o Grupo de Trabalho Indígena da OAB/RJ, a Fundação Nacional Pro-Memória e a Sudelpa na consulta que

${ }^{5} \mathrm{~A}$ respeito das violações de direitos indígenas durante a ditadura militar ver VALENTE, Rubens. Os fuzis e as flechas: história de sangue e resistência indígena na ditadura. Coleção arquivos da repressão no Brasil. 1 ed. São Paulo: Companhia das Letras, 2017. Ver, ainda o Relatório Figueiredo, disponível em:< https://www.documentosrevelados.com.br/geral/relatorio-figueiredo-na-integra/>.
} 
muito pequeno de indígenas possuía algum conhecimento sobre as estruturas jurídicas, políticas e administrativas do Estado Brasileiro, o que impedia qualquer participação em termos efetivamente igualitários. Dispostos a ter voz diante de uma estrutura que nunca os ouviu, desejavam falar, na constituinte, sobre as demarcações de suas terras, a educação escolar de seus filhos, a singularidade de suas culturas, a disponibilização econômica de suas terras e seus recursos naturais, as grandes obras em seus territórios, as remoções de suas aldeias e a atividade garimpeira e mineratória.

As lideranças indígenas, e seus parceiros ( $\mathrm{BBA}, \mathrm{CIMI}$, Conage, SBPC), desejavam inscrever na constituição o direito originário sobre suas terras e o fim ao caráter assimilacionista e tutor da política indigenista, que os definia como grupos incapazes e, de certo modo, anacrônicos do positivismo evolucionista das décadas anteriores. Tal inscrição partiu-se do principio de que o direito originário é "precedente e superior a qualquer outro que, eventualmente, se possa ter constituído sobre o território dos índios ...", bem como que a demarcação das terras "tem única e exclusivamente a função de criar uma delimitação espacial da titularidade indígena [...]. A demarcação não seria constitutiva, "aquilo que constitui o direito indígena sobre as suas terras é a própria presença indígena e a vinculação dos índios à terra [...]" (ANTUNES, 1996).

Assim, os anos de 87 e 88 registraram a primeira Assembleia Nacional Constituinte da qual participaram, ainda que sem voto, representantes indígenas. Um momento inédito no qual os indígenas de diversos povos posicionaram-se diretamente no diálogo com uma estrutura que, desde o século XVI, legislava sobre suas vidas sem consultá-los, e que não se moveria tão facilmente para tal ${ }^{6}$.

A organização da Constituinte foi liderada pela coalizão autodenominada Aliança Democrática (partidariamente representada pela coalizão PMDB-PFL e institucionalmente pelo Governo José Sarney) (ROCHA, 2013). Apesar de nova, ela representava a composição de forças cujas posições e emblemas mantinham o padrão da velha ordem, o período autoritário da ditadura militar no qual, lembre-se, ao menos 8 mil índios foram mortos ${ }^{7}$. Ainda que isso não seja suficiente para comprometer as

\footnotetext{
${ }^{6} \mathrm{~A}$ respeito da legislação indigenista no Brasil Colônia e também nas Constituições anteriores ver CUNHA, Manuela C. e BARBOSA, Samuel (Org.) Direitos dos Povos Indígenas em Disputa. São Paulo: Editora Unesp, 2018, p. 363 e SANTANA, Carolina Ribeiro. "Pacificando" o direito: desconstrução, perspectivismo e justiça no direito indigenista. Dissertação de Mestrado, PUC-RJ. 2010, p. 55 - 78 Disponível em: http://pucrio.summon.serialssolutions.com/\#!/search?ho=t\&q=CAROLINA\%20RIBEIRO\%20SANTANA\&I=br 7 BRASIL. Comissão Nacional da Verdade. Vol. II. Texto 5, p. 205. Disponível em: http://cnv.memoriasreveladas.gov.br/images/pdf/relatorio/Volume\%202\%20-\%20Texto\%205.pdf. Acesso em 05 de ago. 18.
} 
convicções mudancistas do grupo, convém ter em mente que o ritmo de uma mudança é, em grande parte, regulado pela composição da elite que a dirigiu (LESSA, 1986). Sob esta organização a Constituinte se estendeu por 612 dias, processou mais de 62.000 emendas, teve cinco rodadas completas de votação apenas no plenário que preenchem 327 volumes arquivados na biblioteca da Câmara Federal (GOMES, 2013).

A primeira versão de um dispositivo constitucional que impulsionou as discussões em torno dos direitos territoriais indígenas foi produto da Comissão Afonso Arinos ${ }^{8}$ que, apresentou sua proposta em setembro de 1986. Elaborada pelo jurista José Afonso da Silva, a proposta estava em conformidade, em diversos pontos, com o que vinha sendo discutido pelas lideranças indígenas ${ }^{9}$, vez que o jurista a submeteu a diversas organizações indigenistas que com os indígenas dialogavam a esse respeito (ver nota 5). Em dezembro do mesmo ano a União das Nações Indígenas apresentou uma proposta à comissão Arinos ressaltando ou modificando determinados pontos, como a substituição da expressão silvícolas por índios, o destaque para o caráter exclusivo dos indígenas no usufruto das riquezas do solo e subsolo, o acréscimo da natureza jurídica de bens públicos federais indisponíveis às terras indígenas, a ênfase na legitimidade de indígenas ou comunidades indígenas enquanto partes ingressantes em juízo para defesa de seus interesses e o destaque na prevalência de seus usos, costumes e tradições às previsões legais comuns em atos e negócios. A proposta contemplava, portanto, a previsão da inalienabilidade das terras por eles ocupadas, a possibilidade de exploração das riquezas naturais das terras pelos indígenas; a nulidade e extinção de efeitos jurídicos decorrentes de negócios que tenham por objeto tais terras; a intervenção do Ministério Público nas ações judiciais nas quais indígenas estivessem envolvidos, bem como o reconhecimento de ações judiciais propostas por indígenas ou grupos de indígenas.

O Anteprojeto elaborado pela Comissão absorveu em seu texto diversas sugestões apresentadas pelos representantes dos povos indígenas, mas cedeu à continuidade da tutela estatal, mantendo a restrição da capacidade civil dos indígenas,

\footnotetext{
8 Instituída em 18 de julho de 1985 para elaborar um anteprojeto de constituição, como ocorrera em outras constituintes brasileiras, a Comissão Provisória de Estudos Constitucionais, também conhecida como Comissão dos Notáveis, foi mal vista por diversos setores da sociedade. Ver ROCHA, Antônio Sérgio. A genealogia da Constituinte: do autoritarismo à redemocratização. Lua Nova. Revista de Cultura e Política. Vol. 88, 2013, p. 65.

${ }^{9}$ BRASIL. Anteprojeto de Constituição - Comissão Provisória de Estudos Constitucionais. Disponível em: https://www.camara.gov.br/internet/constituicao20anos/DocumentosAvulsos/vol-219.pdf Acesso em 27 de julho de 2018.
} 
uma vez que condicionava a validade jurídica dos contratos por eles firmados à participação obrigatória de suas organizações federais protetoras (art. 382, § $3^{\circ}$ ). 0 texto, todavia, jamais foi remetido formalmente à Constituinte. Embora encomendado pelo Executivo, "seus conteúdos parlamentaristas, democratizantes e 'progressistas'"10 não se afeiçoavam às expectativas do Presidente da República, José Sarney.

Veja-se o que conta Gisele Cittadino sobre este evento (CITTADINO, 2004):

“É verdade que sempre foi pública a discordância de Sarney em relação ao parlamentarismo, mas sua decisão de não enviar o anteprojeto da Comissão ao Congresso Constituinte parece estar ancorada em mais de uma razão. A declaração do deputado José Genoíno, do PT de São Paulo, ao jornal Correio Brasiliense, em 10/6/88, resume bem estes motivos: 'Para falar a verdade, 0 anteprojeto dos Notáveis é bem melhor que o texto aprovado pela Comissão de Sistematização, de uma maneira Geral. O Presidente Sarney o engavetou justamente porque era avançado demais.' Ainda que não tenha sido formalmente encaminhado à Constituinte, para servir de subsídio, como inicialmente previsto por Tancredo Neves, o anteprojeto da Comissão não foi esquecido. Das mais variadas formas ele circulava nos bastidores do Congresso. Informalmente, partes significativas do seu texto foram copiadas por constituintes, o que levou o deputado Manuel Moreira, do PMDB paulista, a observar: 'No lugar de plagiar, vamos examinar logo o original.'”

A Comissão desagradou também à $\mathrm{OAB}$, visto que a Ordem a via como uma ameaça à plena participação da população no processo e de restrição da margem de atuação dos constituintes. O jurista Raymundo Faoro, ex-presidente da $\mathrm{OAB}$, foi uma das principais vozes contra a Comissão referindo-se a ela como um "anacronismo" e como "absolutamente ilegítima". Para ele a Comissão "negava a titularidade do povo no poder constituinte" e fazia parte do "surrado repertório político das elites brasileiras"11. Uma significativa mudança de posicionamento para a instituição que apoiou o golpe de 64 e, sequer, manifestou-se contra o Al-5 em seu congresso realizado em 1970, em São Paulo ${ }^{12}$.

10 “[...]a Comissão Arinos foi mal recebida pelos progressistas, que viam aí uma tentativa espúria de interferência presidencial na definição da agenda temática da futura Constituinte. A tentativa de impedir a aprovação da Emenda Sarney foi mal sucedida; já com a Comissão Arinos passou-se algo singular: alvo de grande polêmica na imprensa escrita, sua composição foi adequada ao gosto dos interesses emergentes no processo de transição, seus trabalhos foram intensamente acompanhados, noticiados, criticados [...]" (PILATTI, 2008. p. 21).

11 Jornal do Brasil. 12/07/85 (apud LESSA, 1986)

12 Flávio Bierrencach, em depoimento concedido em 2010 à equipe do Cedec em São Paulo (apud ROCHA, 2013, p. 41). 
A Subcomissão de Negros, Populações Indígenas, Pessoas Deficientes e Minorias

Presidida pelo deputado Ulisses Guimarães a Constituinte foi dividida em oito Comissões, cada qual com suas subcomissões (ao todo vinte e quatro) ${ }^{13}$. As questões indígenas ficaram primordialmente a cargo da Subcomissão de Negros, Populações Indígenas, Pessoas Deficientes e Minorias (SNPIPDM) ${ }^{14}$, que compunha a Comissão da Ordem Social.

Instalada no dia sete de abril de 1987 a primeira reunião da SNPIPDM foi marcada pela falta de interesse dos parlamentares, registrada em ata pelo presidente recém-eleito, constituinte Ivo Lech, e pela ausência da imprensa, fato registrado pelo constituinte Hélio Costa, que se disse também surpreso com o desinteresse dos membros da Assembleia Nacional Constituinte e da imprensa em geral na Subcomissão, ao passo que, "a grande cobertura é dada às Subcomissões que tratam de assuntos ligados a interesses de grandes grupos econômicos e financeiros"15. ${ }^{15}$ desinteresse, tanto dos constituintes quanto da mídia se repetiu nas reuniões seguintes.

Durante os dias seguintes foi debatida e elaborada uma proposta - a Proposta Unitária relativa aos direitos indígenas. A Proposta Unitária foi elaborada no escritório do Instituto de Estudos Sócio Econômicos - Inesc, em Brasília, e contou com a participação de representantes da União das Nações Indígenas - UNI, Conselho Indigenista Missionário - CIMI, Associação Brasileira de Antropólogos - ABA, Centro Ecumênico de Documentação e Informação - Cedi, Coordenadoria de Terras Indígenas Desenvolvimento e da Reforma Agrária - CTI/Mirad, Comissão Pró Yanomami - CCPY, Coordenação Nacional de Geólogos - Conage, Procuradoria-Geral da República e indígenas residentes em Brasília. Na reunião seguinte, no dia 22 de abril, esta Proposta Unitária relativa aos direitos indígenas foi entregue por cerca de 40 lideranças indígenas (dentre as quais Kayapó, Fulni-ô, Krenak e Pataxó) à SNPIPDM. Durante esta reunião os constituintes também debateram a viabilidade de conciliar os prazos regimentais e um novo modelo de participação popular, por meio de audiências públicas realizadas in

\footnotetext{
${ }^{13} \mathrm{http}: / /$ www2.camara.leg.br/atividade-legislativa/legislacao/Constituicoes_Brasileiras/constituicaocidada/o-processo-constituinte/lista-de-comissoes-e-subcomissoes 14 Doravante denominada SNPIPDM. Importantes assuntos indígenas foram também tratados nas subcomissões de Nacionalidade, da Soberania e das Relações Internacionais; Regime da Propriedade do Subsolo e da Atividade Econômica; da Educação, Cultura e Esportes. As questões territoriais, todavia, foram tratadas primordialmente na SNPIPDM.

15 BRASIL. DIÁRIO DA ASSEMBLÉIA NACIONAL CONSTITUINTE (Suplemento); 07 de abril de 1987, p. 179. Disponível em: < http://imagem.camara.gov.br/Imagem/d/pdf/sup53anc01mai1987.pdf\#page=179>. Acesso em 31 de jul. de 18.
} 
loco, mas as datas regimentais atropelaram esta possibilidade permitindo pouquíssimas dessas audiências. Ainda nesta reunião pronunciou-se o cacique Raoni Kayapó Mentuktire ${ }^{16}$ :

[...] o meu povo está morrendo na mão do seu povo [...] a vida de vocês não é boa para nós índios. Nós temos direito à terra [...]. Nós não queremos a casa de vocês, eu não quero a casa de madeira nem a terra ruim, onde meu povo não pode entrar. Seu povo não pode matar mais o meu povo. Quando o seu povo mata o meu povo, temos que lutar para matar. Vocês têm que acreditar nas minhas palavras, porque eu estou acreditando muito nas palavras de vocês $[\ldots]^{17}$.

Assim como Raoni, as demais lideranças acreditavam nos constituintes e exigiam seus direitos. Florestan Fernandes afirmou sobre a participação de cidadãos nas Subcomissões para defender o democratismo e os interesses coletivos que as pessoas estavam a exigir o "preto no branco", uma constituição analítica e clara que desemboque, "no mínimo, em uma revolução política dentro da ordem. E é exatamente isso que a massa de parlamentares conservadores repudia" (FERNANDES, 1989).

Grande parte dos constituintes que compuseram a SNPIPDM pareciam ter consciência da importância de uma experiência de coprodução legislativa em parceria com os indígenas na busca por uma sociedade mais fraterna. O constituinte Carlos Sabóia pontuou, por exemplo:

[...] se não formos capazes de entender o significado da presença das populações indígenas de todo o Brasil, aqui hoje representadas nesta Subcomissão, não seremos capazes de dar um passo à frente, um passo de democratizar este País; não haverá democracia neste País sem a presença dos índios nesta sala, durante toda a realização da Constituinte e durante a realização da escrita do novo texto constitucional (idem).

Na reunião do dia 23 de abril a Subcomissão assistiu a uma palestra da antropóloga Manuela Carneiro da Cunha, presidente da Associação Brasileira de Antropologia à época. Carneiro da Cunha contextualizou historicamente a legislação correlata ao tema e explicitou a conturbada relação do Estado brasileiro com os povos indígenas. Também refletiu acerca de como a nova Carta Constitucional deveria tratar

\footnotetext{
${ }^{16}$ Acho importante destacar a displicência nos registros dos nomes dos indígenas, das etnias e das aldeias, não raro grafadas de modo equivocado ao longo das atas da constituinte. O próprio nome do conhecido cacique Raoni, encontra-se grafado como "Daoni" em alguns trechos.

17 BRASIL. Diário da Assembleia Nacional Constituinte (Suplemento); 23 de abril de 1987, p. 127. Disponível em: < http://imagem.camara.gov.br/Imagem/d/pdf/sup53anc01mai1987.pdf\#page=179>. Acesso em $31 \mathrm{de}$ jul. de 18.
} 
minorias e denunciou as ameaças dos atrasos nas demarcações e da cobiça por explorações de minérios nas terras indígenas.

(...) essa política de não-demarcação deixa a descoberto uma série de terras para as quais os índios têm atualmente direitos constitucionais, e esperamos que a nova Constituição mantenha esses direitos. Seria uma quebra de toda a tradição jurídica se esta Constituição democrática não desse as mesmas garantias que Constituições autoritárias asseguraram. 0 que implica essa não demarcação? Por que não se demarcou? É bom que se diga. A demarcação estava prevista no Estatuto do Índio, que é de 1973, que previa 5 anos para que se completassem todas as demarcações. No entanto, estamos em 87 , e dei as cifras atuais, $32 \%$ das terras identificadas apenas estão demarcadas. Não se demarca exatamente porque os interesses são muito grandes. Há interesses contra a demarcação, ou então há interesses em demarcar incorretamente, ou seja, reduzindo fortemente as terras que a Constituição garante aos índios ${ }^{18}$.

Na oitava reunião da Subcomissão, em 29 de abril, Dom Erwin Kräutler, do CIMI, relatou o histórico violento do Estado com as populações indígenas, denunciou o assédio de mineradoras, mencionou a falta de interesse político na demarcação de suas terras, afirmando que muitas só foram demarcadas por serem condicionantes de salvaguardas de agências multilaterais como o Banco Mundial, e denunciou a militarização das questões indígenas em região de fronteiras. Seguiu-se, no mesmo dia, um debate acerca da mineração em terras indígenas e, ainda, sobre o impacto da atuação de missionários religiosos sobre identidade cultural. Em seguida, o professor Carlos Frederico Marés palestrou sobre o direito indigenista nas constituições anteriores, sobre a insuficiência do direito privado e do direito público para a compreensão da realidade indígena e reiterou a importância de se passar a garantir a autonomia indígena para pleitear em juízo:

[...] o direito de ação é dado a poucas pessoas na questão indígena. É dado, hoje, legalmente, às nações indígenas, mas essas nações, muitas vezes, não têm sequer condição de constituir um advogado, como é o caso especificamente, da nação lanomami, cujo entendimento da língua brasileira, para não dizer do resto da cultura, os impede de sequer contratar um advogado para impor-se com uma defesa judicial de suas terras ou de seus direitos ameaçados ou seus direitos violados. Por isso, é necessário que se dê garantias a que organizações índias não específicas, por exemplo, a União das Nações Indígenas ou de outras organizações que se formem de índios, possam ingressar em juízo, para fazer com que o Judiciário se manifeste em agressões a direitos indígenas. É necessário, também, que se dê, dentro da estrutura do Estado brasileiro, possibilidade de que essa estrutura se movimente por si em defesa dos direitos. E nós entendemos

18 BRASIL. Diário da Assembleia Nacional Constituinte (Suplemento); 05 de maio de 1987, p. 133. Disponível em: < http://imagem.camara.gov.br/Imagem/d/pdf/sup95anc16jul1987.pdf\#page=134>. Acesso em $01 \mathrm{de}$ ago. 18. 
que para movimentar-se por si, dentro do Judiciário, ninguém mais do que o Ministério Público é capaz de fazê-lo.

Seguiu-se, novamente, um debate em torno da questão das riquezas minerais nos subsolos das terras indígenas e a fala da professora Manuela Carneiro da Cunha, que retomou a denúncia de Dom Erwin acerca do excesso de militarização das demarcações de terras indígenas nas faixas de fronteiras. Nesta sessão ainda a Coordenação Nacional de Geólogos - Conage, apresentou proposta de exploração mineratória em terras indígenas a qual, ressaltando a autonomia dos povos, previa o interesse da União e a não participação de empresas privadas ${ }^{19}$.

Na 11a Reunião ordinária, em 05 de maio do mesmo ano estiveram presentes indígenas e indigenistas como Pangram Ubenkran-Grem, Estevão Taukane Bakairi, Nelson Sarakura Pataxó, Gilberto Macuxi, Davi Kopenawa Yanomami, Kromare Metotire, Pedro Kaingang, Valdomiro Terena, Hamilton Lopes Kaiowá, Antonio Apurinã e Ailton Krenak, além do antropólogo Eduardo Viveiros de Castro. Estes que falaram discursaram sobre a necessidade da garantia da demarcação e da proteção de terras para a existência física e cultural dos diversos povos, denunciaram o descaso das autoridades competentes, o aumento das violências sofridas, os impactos de grandes empreendimentos, as ameaças advindas de atividades madeireiras e garimpeiras e a importância de se atentar para as diferentes realidades e especificidades dos problemas vividos pelos indígenas em cada região do país ${ }^{20}$.

Nessa mesma audiência pública foi apresentada uma proposta elaborada pela comunidade do povo Bakairi, do Mato Grosso contendo diversas inovações não presentes na Proposta Unitária. Os Bakairi propuseram o reconhecimento das línguas indígenas como idiomas oficiais (uma nação multilinguística), a natureza jurídica das terras indígenas como propriedade coletiva dos índios, a necessidade de autorização direta dos índios quanto à entrada de pessoas nas terras, a exclusividade indígena na decisão acerca de construção de rodovias em seus territórios, as vagas especiais em universidades; a previsão de recuperação da vegetação das áreas indígenas por meio de programas federais e a criação de órgãos, de âmbito estadual, destinados a tratar

19 BRASIL. Diário da Assembleia Nacional Constituinte (Suplemento); 05 de maio de 1987, p. 144 - 150. Disponível em: < http://imagem.camara.gov.br/Imagem/d/pdf/sup53anc01mai1987.pdf\#page=179>. Acesso em 31 de jul. de 18.

20 BRASIL. Diário da Assembleia Nacional Constituinte (Suplemento); 05 de maio de 1987, p. 144 - 150. Disponível em: < http://imagem.camara.gov.br/Imagem/d/pdf/sup53anc01mai1987.pdf\#page=179>. Acesso em 31 de jul. de 18. 
de assuntos indígenas. Outra proposta também apresentada foi a de Valdomiro Terena resultante de um encontro de lideranças indígenas realizado em Campo Grande; essa proposta ia ao encontro da proposta dos Bakairi, além de também tratar da questão do direito ao voto universal, direto e secreto para os indígenas.

O antropólogo Eduardo Viveiros de Castro entregou proposta de texto constitucional elaborada pela Sociedade Brasileira para o Progresso da Ciência (SBPC) e denunciou o estranho relacionamento do Estado Brasileiro com os indígenas. Disse ele que os indígenas para o Estado são, antes, objeto de atenção do Conselho de Segurança Nacional que da Funai e enfatizou o quão irônico era o paradoxo de o Estado não reconhecer os povos indígenas como nações e ao mesmo tempo dispensarIhes o tratamento de nações inimigas ${ }^{21}$.

Em 06 de maio realizou-se uma audiência extraordinária com as populações indígenas na aldeia Gorotire, no sul do Pará. As falas dos indígenas sequer estão registradas em ata, da qual consta apenas:

A comitiva foi recepcionada por todos os caciques da reserva que a conduziu à Taba dos Guerreiros onde foram ouvidos os pleitos daquela comunidade indígena, tais como: escritura definitiva das terras da reserva de conformidade com o acordo firmado com o então Ministro do Interior Ronaldo Costa Couto, providências junto às autoridades competentes para impedir a poluição dos rios com mercúrio proveniente da mineração do ouro em garimpos encravados no interior da reserva e uma melhor assistência médica. [...] Em seguida o Senhor Presidente foi nomeado cacique, presenteado com um cocar e homenageado com danças típicas dos Caiapós. Foi constatado pela Subcomissão um desmatamento indiscriminado no interior da reserva por parte do Grupo Sebba, com conivência da FUNAl, em troca são oferecidas aos índios casas de alvenaria de valor muito aquém do real, visto que são extraídas madeiras nobres, aliada a este fato está uma cada vez mais acelerada descaracterização dos costumes indígenas ${ }^{22}$.

Oitenta e nove emendas foram apresentadas ao anteprojeto de Constituição elaborado pelo Relator, Deputado Alceni Guerra, que o modificou resultando no texto aprovado em 25 de maio de $1987^{23}$. No texto final, no que diz respeito aos direitos indígenas destacam-se como resultado da subcomissão e do relatório final: a garantia do caráter pluriétnico da sociedade brasileira, a submissão da direção do órgão indigenista

\footnotetext{
21 Idem, p. 159.

22 BRASIL. Diário da Assembleia Nacional Constituinte (Suplemento); 05 de maio de 1987, p. 134. Disponível em: < http://imagem.camara.gov.br/Imagem/d/pdf/sup95anc16jul1987.pdf\#page=134>. Acesso em $01 \mathrm{de}$ ago. 18.

${ }^{23}$ BRASIL. Diário da Assembleia Nacional Constituinte (Suplemento); 05 de maio de 1987, p. 151. Disponível em: < http://imagem.camara.gov.br/Imagem/d/pdf/sup103anc24jul1987.pdf\#page=146>. Acesso em $01 \mathrm{de}$ ago. 18.
} 
oficial a um conselho de representações indígenas, a garantia aos índios da realização de cata, faiscação e garimpagem em suas terras, a garantia da consulta aos indígenas para os casos de realização de pesquisas e exploração pela União de recursos existentes em terras indígenas, a garantia do prazo de um ano para a tramitação total de um processo de demarcação territorial, o usufruto indígena exclusivo das riquezas naturais do solo e do subsolo, a proibição de remoção de grupos indígenas de suas terras - salvo nos casos excepcionais e a garantia aos "índios, suas comunidades e organizações" da capacidade postulatória.

\section{Resistindo na Comissão da Ordem Social}

O texto então seguiu para a Comissão da Ordem Social onde receberam emendas supressivas as questões da plurietnia do Estado brasileiro, a expressão "nações indígenas" 24 e a subordinação do órgão indigenista oficial a um conselho de indígenas e o usufruto exclusivo dos indígenas sobre o subsolo. Para o Deputado constituinte Oswaldo Almeida (PL/RJ)

"[...] evidencia-se, como altamente nocivo ao desenvolvimento harmonioso da sociedade brasileira a inclusão do conceito de nações indígenas na nova Carta. Trata-se, por outro lado, de um grave risco a ser assumido, proporcionando, por exemplo, a oportunidade de formação de enclaves dentro do território nacional."

Veja-se o que disse o mesmo deputado a respeito da plurietnia:

Há o reconhecimento histórico da formação básica da nacionalidade brasileira ter sua origem na plurietnia das três predominantes (branca, índia, negra). Desde o inicio da formação da sociedade brasileira processou-se a miscigenação natural entre as três raças, que, de certa forma está criando o tipo brasileiro, ainda em desenvolvimento. A inclusão do conceito de sociedade brasileira pluriétnica, na futura constituição, uma tentativa artificial de estancar este desenvolvimento; que vem se processando ao longo dos tempos, sem conflitos entre as raças. ${ }^{25}$

A capacidade relativa dos indígenas foi o argumento trazido pelo dep. Eraldo Trindade (PFL) defender a não subordinação do órgão indigenista oficial a um conselho

24 BRASIL. Diário da Assembleia Nacional Constituinte. Vol. 184.Emendas oferecidas ao substitutivo VII Comissão da Ordem Social. Emenda Supressiva 750398-9, p. 93. Disponível em: < http://imagem.camara.gov.br/Imagem/d/pdf/sup95anc16jul1987.pdf\#page=134>. Acesso em 01 de ago. 18 25 BRASIL. Diário da Assembleia Nacional Constituinte. Vol. 184. Emendas oferecidas ao substitutivo VII Comissão da Ordem Social. Emenda Supressiva 7S0398-9, p. 93. Disponível em: http://imagem.camara.gov.br/Imagem/d/pdf/sup95anc16jul1987.pdf\#page=134. Acesso em 01 de ago. 18. 
de indígenas ${ }^{26}$.

Na medida em que o texto avançou para o debate em outras instâncias da Constituinte as valorosas trocas de conhecimentos propiciadas pelos diálogos realizados com os indígenas e com especialistas no âmbito da Subcomissão foram ficando rarefeitas. Pouco a pouco diversos dispositivos produzidos a partir daquelas trocas foram sendo desconsiderados ao longo do processo. A fala, novamente, do Dep. Oswaldo Almeida (PL/RJ) durante a votação do Substitutivo do Relator na Comissão da Ordem Social explicita isso:

[...] infelizmente não tivemos o tempo suficiente, a nível de Comissão, para termos, todos, as mesmas oportunidades de esclarecimento, a nível técnico, como foi o caso da Subcomissão que tratou das minorias. Eu, por exemplo, que fiz parte da Subcomissão de Saúde, somente agora, há poucos instantes, é que vim tomar conhecimento, me identificar ou me aprofundar no problema das minorias. E acho que a maioria da nossa Comissão se encontra dentro desse contexto. E por isso mesmo o nosso enfoque sobre esse assunto, que deve constar da nossa Constituição, terá que ficar um pouco fora dessas profundezas antropológicas e sociológicas ${ }^{27}$.

Em 12 de junho de 1987 o texto do Substitutivo da Comissão de Ordem Social fora aprovado. Manteve-se o caráter pluriétnico da sociedade brasileira, (por 51 votos a 10), o Conselho a que se subordinaria o órgão indigenista oficial tornou-se paritário ("indígenas, União e sociedade" ${ }^{28}$ ) e ficou garantida aos indígenas a realização de garimpagem em suas terras. Destaque-se, ainda, um grande avanço para a época, a garantia de que a realização de pesquisa, lavra ou exploração de minérios em terras indígenas dependeriam de autorização das populações envolvidas e da aprovação do Congresso Nacional.

Outra frente parlamentar também atuava em defesa dos direitos indígenas, não apenas a que compôs a subcomissão de Negros, Populações Indígenas, Pessoas Deficientes e Minorias. Os parlamentares que compuseram a Subcomissão de Nacionalidade, Soberania e Relações Internacionais, agora defendiam os direitos indígenas nas reuniões da Comissão da Soberania dos Direitos e Garantias do Homem e da Mulher. Nesta, a proposta da plurietnia também enfrentou oposições. O deputado

26 BRASIL. Diário da Assembleia Nacional Constituinte. Vol. 184. Emendas oferecidas ao substitutivo VII Comissão da Ordem Social. Emenda Supressiva 7S0202-8, p. 48. Disponível em: http://imagem.camara.gov.br/Imagem/d/pdf/sup95anc16jul1987.pdf\#page=134. Acesso em 01 de ago. 18. 27 BRASIL. Diário da Assembleia Nacional Constituinte. Atas das Comissões. 5 de agosto de 1987, p. 141. Disponível em: http://imagem.camara.gov.br/Imagem/d/pdf/sup115anc05ago1987.pdf\#page=120 Acesso em 01 de ago. 18.

28 É curioso notar que após inúmeros debates em torno da unidade nacional e lançando mão do mito da miscigenação coloca-se neste dispositivo os indígenas como algo diferente da "sociedade". Observe-se que há previsão para os representantes dos índios, os da União e os da sociedade. 
Francisco Rollemberg (PMDB-SE), por exemplo, argumentou no sentido de que todos os índios teriam que participar da vida nacional e que juntos, índios e não-índios, teriam que construir uma "grande nação", falando a mesma língua, invocando o mesmo Deus e a mesma religião ${ }^{29}$.

A esta altura dos trabalhos, às vésperas de se iniciarem os debates na Comissão de Sistematização, afirmou Florestan Fernandes que o resultado dessas duas primeiras etapas de trabalho apresentava inúmeras contradições internas que com muita dificuldade se unificariam. Isso pois, segundo o renomado cientista social, a massa reacionária da burguesia aliava-se aos elementos retrógrados externos e à sabotagem sistemática do governo. "Os radicais do PMDB não podem recuar de suas posições, de defesa do "mudancismo", porém não possuem potencial (isolados ou em aliança com os partidos de esquerda) para vencerem os adversários" (FERNANDES, 1989, p.109), afirmou.

\section{Os embates na Comissão de Sistematização}

A Comissão de Sistematização, próximo obstáculo a ser superado pelas propostas referentes aos direitos indígenas, recebia os anteprojetos resultantes das demais Comissões e ficava responsável por elaborar um anteprojeto final a ser enviado para o plenário. Nesta instância foram suprimidos o caráter pluriétnico da sociedade brasileira, o conselho paritário a que estaria submetido o órgão indigenista oficial, a necessidade de autorização dos indígenas para a realização de pesquisa, lavra ou exploração de minérios em suas terras e a permissão de realização de garimpo pelos indígenas. "Questões de soberania nacional" foram incluídas ao texto como permissivas à remoção de grupos indígenas; na comissão de Ordem Social constavam apenas epidemias e catástrofes. Ainda como adição aparece agora a vedação dos direitos previstos na Constituição aos indígenas com "elevado estádio [sic] de aculturação".

Argumentos nacionalistas, como a unidade nacional em torno de um só povo, foram bastante utilizados pelos constituintes a todo momento que, não raro, conjecturaram ameaças à soberania nacional. No início de agosto de 1987 o jornal 0 Estado de São Paulo iniciou uma campanha contra os direitos indígenas na Constituinte

29 Jornal do CIMI, “Porantin”, Brasília, ano X, n. 108, mai. 1987; p. 3 (apud LACERDA, 2008, p.84) 
e a favor dos interesses das empresas mineradoras e a exploração mineratória em terras indígenas. Coincidência ou não este era também o período em que se abriu o prazo para a apresentação de emendas ao Projeto de Constituição da Comissão de Sistematização. A campanha do Estadão acusou o CIMI de propor a divisão do Brasil, e de possuir interesses obscuros a fim de futuramente internacionalizar as terras indígenas. Para o periódico o $\mathrm{CIMI}$ estaria usando os povos indígenas para implementar um conceito restrito de soberania na nova Constituição. As acusações deram ensejo à abertura de uma Comissão Parlamentar de Inquérito da qual resultou relatório afirmando ter tido o "Estadão" intenções fraudulentas, denúncias sem fundamento e citação da autoridade competente para investigar possível caso de falsidade ideológica (LACERDA, op.cit, pp. 92-96).

Dentre as 83 emendas admitidas ${ }^{30}$ na Comissão de Sistematização, duas relacionavam-se à questão indígena (n.o 39 e 40). Uma delas, encabeçada pela UNI e de responsabilidade de associações e instituições de antropólogos, geólogos e a SBPC, versava sobre serviço de apoio às populações indígenas; e a outra, de responsabilidade do CIMI, abordava o reconhecimento de nações indígenas.

A respeito da emenda n. -39 afirmou o assessor do CIMI, Julio Gaiger:

A Emenda Popular n. 39 afirma, categoricamente, que o reconhecimento das nacionalidades específicas dos membros das nações indígenas não afeta a sua cidadania brasileira. [...] admitir o caráter plurinacional do Brasil implica renunciar ao colonialismo interno e abdicar da assimilação forcada como destino único oferecido às populações indígenas. ${ }^{31}$.

Em resposta manifestou-se o deputado José Dutra (PMDB-AM)

[...] não posso admitir, de forma alguma, a tese que V. S.a levanta, quando prega a condição do Estado brasileiro como plurinacional. Por que, Dr. Gaiger? [...] Não posso, de forma alguma, admitir que se insira dentro do contexto nacional qualquer instituição, qualquer outra nação que venha ferir a soberania brasileira, de forma alguma. Isso seria negar a luta, seria

\footnotetext{
30 Resultante de uma emenda ao Regimento Interno, as emendas populares dependiam de uma quantidade tal de imposições que deixa transparecer o temor de seu potencial. Sobre as exigências afirmou Francisco Whitaker: "Já que a meninada está querendo tanto, vamos lá. Põe aí, mas põe uma dificuldade: 30 mil assinaturas, no mínimo, vindo de pelo menos 5 Estados. E ninguém podia assinar mais de 3 emendas. $E$ outras barreiras desse tipo, como todas as indicações de endereço, título de eleitor, etc. Nada de RG, não. Era um negócio bem completo. E tinham que ser apoiadas pelo menos por 3 entidades da sociedade civil, para realmente dificultar". Apesar disso, foram apresentadas 122 emendas populares à Mesa Diretora da Assembleia que, após verificação, admitiu 83 propostas que atendiam às exigências regimentais da Constituinte. 12.277.423 assinaturas foram computadas "o que mesmo considerando o limite máximo de três subscrições por eleitor, implicou o envolvimento superior a 4 milhões de cidadãos!" (LOPES, 2008, p. 57).

31 BRASIL. Diário da Assembleia Nacional Constituinte. Atas das Comissões. Comissão de Sistematização., p. 577.Disponível em: http://www2.camara.leg.br/atividadelegislativa/legislacao/Constituicoes_Brasileiras/constituicao-cidada/o-processo-constituinte/comissao-desistematizacao/COMSist23ext27011988.pdf . Acesso em 01 de ago.18.
} 
negar todo o passado de luta de nossos ancestrais, daqueles como os bandeirantes, que invadiram o Oeste, buscando dilatar a nossa fronteira, preservando os nossos interesses, para que hoje tivéssemos um País deste tamanho, falando a mesma língua, o mesmo idioma, de norte a sul e de leste a oeste ${ }^{32}$.

As Emendas Populares em defesa dos direitos indígenas foram as últimas a serem defendidas na pauta do Plenário da Comissão de Sistematização, o que ocorreu num Plenário esvaziado, com menos de um terço de seus integrantes. Nesse momento registrou-se o antológico discurso do Coordenador da UNI, Ailton Krenak, que durante seu discurso pintou o rosto com tinta preta à base de jenipapo, usada nas pinturas tradicionais dos povos indígenas:

(...) Ao longo desse período, a seriedade com que trabalhamos e a reciprocidade de muitos dos Srs. Constituintes permitiram a construção, a elaboração de um texto que provavelmente tenha sido o mais avançado que este País já produziu com relação aos direitos do povo indígena. Esse texto procurou apontar para aquilo que é de mais essencial para garantir a vida do povo indígena. Os Srs. sabem, V. Exs sabem que o povo indígena está muito distante de poder influenciar a maneira que estão sugerindo os destinos do Brasil. Pelo contrário. Somos talvez a parcela mais frágil nesse processo de luta de interesse que se tem manifestado extremamente brutal, extremamente desrespeitosa, extremamente aética. Espero não agredir, com a minha manifestação o protocolo desta Casa. Mas acredito que os Srs. não poderão ficar omissos. Os Srs. não terão como ficar alheios a mais esta agressão movida pelo poder econômico, pela ganância, pela ignorância do que significa ser um povo índígena. ( $\mathrm{S} \mathrm{Sr}$. Krenak inicia processo de caractenzação - pintura facial.) (...) Hoje somos alvo de uma agressão que pretende atingir na essência, a nossa fé, a nossa confiança. Existe dignidade, ainda é possível construir uma sociedade que saiba respeitar os mais fracos, que saiba respeitar, aqueles que não têm dinheiro, mas mesmo assim, mantêm uma campanha incessante de difamação. Um povo que sempre viveu à revelia de todas as riquezas, um povo que habita casas cobertas de palha, que dorme em esteiras no chão, não deve ser de forma nenhuma contra os interesses do Brasil ou que coloca em risco qualquer desenvolvimento. O povo indígena tem regado com sangue cada hectare dos oito milhões de quilômetros quadrados do Brasil. V. Exas. são testemunhas disso. ${ }^{33}$

O Projeto de Constituição, mesmo após a análise das Emendas Populares, teve seu segundo substitutivo esquematizado de maneira a não refletir os debates travados nas subcomissões, matérias que foram conquistadas depois de muita discussão e votadas nas instâncias anteriores estavam agora esquecidas ou com redação contrária

\footnotetext{
32 Idem, p. 578.

${ }^{3} \mathrm{Na}$ íntegra em BRASIL. Assembleia Nacional Constituinte. 23a Reunião Extraordinária da Comissão de Sistematização; Brasília-DF, Disponível em <http:\|www.congresso.gov.br/anc88/>. p. 558. (Acesso em 12.12.2009).
} 
ao que tinha sido aprovado.

O texto que seguiu para o plenário assim se apresentava:

Art. 268. São reconhecidos aos índios seus direitos originários sobre as terras de posse imemorial onde se acham permanentemente localizados, sua organização social, seus usos, costumes, línguas, crenças e tradições, competindo à União a proteção desses bens.

$\S 1^{\circ}$ Os atos que envolvam interesses das comunidades indígenas terão participação obrigatória de órgão federal próprio e do Ministério Público, sob pena de nulidade.

$\S 2^{\circ} \mathrm{A}$ exploração das riquezas minerais em terras indígenas só pode ser efetivada com autorização do Congresso Nacional, ouvidas as comunidades afetadas, e obriga a destinação de percentual sobre os resultados da lavra em beneficio das comunidades indígenas e ao meio ambiente, na forma da lei.

Art. 269. As terras de posse imemorial dos índios são destinadas à sua posse permanente, cabendo-lhes o usufruto exclusivo das riquezas naturais do solo, dos recursos fluviais e de todas as utilidades nelas existentes.

$\S 1^{\circ}$ São terras de posse imemorial onde se acham permanentemente localizados os índios, aquelas destinadas à sua habitação efetiva, às suas atividades produtivas e as necessárias à sua preservação cultural, segundo seus usos, costumes e tradições.

$\S 2^{\circ}$ As terras referidas no parágrafo anterior são bens inalienáveis e imprescritíveis da União, cabendo a esta demarcá-las.

$\S 3^{\circ}$ É vedada a remoção dos grupos indígenas de suas terras, salvo nos casos de epidemia, catástrofe da natureza e outros similares e de interesse da soberania nacional, garantido o seu retorno quando o risco estiver eliminado.

Art. 270. Os índios, suas comunidades e organizações são partes legítimas para ingressar em juízo em defesa dos interesses e direitos indígenas.

Art. 271. Os direitos previstos neste capítulo não se aplicam aos índios com elevado estádio [sic] de aculturação, que mantenham uma convivência constante com a sociedade nacional e que não habitem terras indígenas. ${ }^{34}$ [grifos nossos]

\section{Algumas baixas no Plenário}

Os trabalhos no Plenário da Assembleia Nacional Constituinte começaram no dia 27 de janeiro de 1988. Um grande número de parlamentares era contrário às propostas dos direitos indígenas e, por essa razão, formou-se a Frente Parlamentar Pró-Índio, coordenada pelo Deputado Tadeu França (PDT-PR), no intuito de combater as

\footnotetext{
34 BRASIL. Assembleia Nacional Constituinte. Substitutivo da Comissão de Sistematização às emendas de Plenário, referente ao Título VIII; Brasília-DF, Disponível em <http:\|www2.camara.leg.br/atividadelegislativa/legislacao/Constituicoes_Brasileiras/constituicao-cidada/o-processo-constituinte/comissao-desistematizacao/segundo-substitutivo-do-relator >. p. 14. (Acesso em 12.12.2009).
} 
articulações do "Centrão" ${ }^{35}$ e da bancada "anti-índio" ${ }^{36}$.

O desgaste de tanto tempo de trabalhos - entre os constituintes e diante da sociedade brasileira - passava a se explicitar no momento em que as propostas foram levadas ao Plenário, acelerando a elaboração constitucional. "A Constituição foi elaborada, de fato, no plenário da Assembleia, especialmente através das fusões que permeavam seu arco ideológico" (LOPES, 2008, p.199).

No início de maio de 88 os Kayapó, que já haviam frequentado a Constituinte, retornam acompanhados com mais de cem outras lideranças indígenas dispostos a aguardar a votação do capítulo "Dos índios". A disputa desse capítulo seria travada com deputados ligados às determinações do Conselho de Segurança Nacional (CSN) ${ }^{37}$ para quem os índios representavam uma ameaça à soberania nacional.

Em 25 de maio de 1988 os indígenas se alinharam formando um corredor polonês à entrada do plenário da Câmara. Eles entregaram aos Constituintes que chegavam o seu material em favor das emendas populares propostas por seus aliados e destaques favoráveis propostos por parlamentares parceiros da causa. Neste dia o debate das matérias indígenas ocorreu na sala da Liderança do PMDB, não tendo sido permitida a entrada dos indígenas que tiveram que aguardar no auditório anexo. Ali receberam assessoria de diversas entidades indigenistas que traduziam em suas línguas a proibição de sua entrada na ala, bem como as discussões acerca da questão territorial indígena.

Diversos parlamentares pretendiam retirar do texto o caráter originário dos direitos territoriais indígenas e deixar apenas os termos "posse imemorial" e "localização permanente", além de tentarem também retornar o debate da incapacidade relativa dos indígenas. O cacique Raoni Mentuktire, que participou ativamente do momento constituinte, abordou, ao saírem da sala, os deputados José Lins e Bonifácio Andrade, ambos representantes do "Centrão" e defensores de propostas restritivas aos direitos indígenas. Perguntou ao deputado Lins: "a verdade, sem mentir, o que você está dizendo lá dentro?". Percebendo que o parlamentar tentava desconversar, Raoni conseguiu, com a diplomacia que lhe é peculiar, que os

35 O Centrão foi a autodenominação dada, a partir de novembro de 1987, pelos integrantes do grupo formado pela fração conservadora do PMDB, usualmente rebelde em face das orientações progressistas do líder, e pelas bancadas do PDS, PFL, PL e, salvo em algumas questões pontuais PDC e PTB; na definição de PILATTI. A Constituinte de 1987-1988... op. cit. p. 4.

36 Álvaro Valle PL-RJ; Moisés Pimentel PMDB-CE; Cleonâncio Fonseca PFL-SE; Gustavo de Faria PMDB-RJ; Jovanni Massini PMDB-PR; Marcelo Cordeiro PMDB-BA.

${ }^{37}$ Bonifácio de Andrada PDS-MG; José Linnas PFL-CE; José Dutra PMDB-AM; Ottomar Pinto PTB-RR. 
parlamentares entrassem em detalhes. Em seguida, conduzindo-os pela mão, os fez cumprimentar todos os caciques Kayapó presentes ${ }^{38}$.

Foram apresentadas diversas emendas que tinham por objetivo retirar do Projeto de Constituição elaborado pela Comissão de Sistematização (mencionado no final da seção anterior) o caráter originário das terras, a intervenção do Ministério Público Federal em favor dos indígenas e a consulta aos indígenas acerca da exploração mineral em suas terras. Compare-se, por exemplo, o texto acima citado com a emenda modificativa n. ㅇ 2P00494-6; o autor, deputado Moyses Pimentel (PMDB), sugeria novo texto ao caput do artigo 268 e do seu $\S 10$ :

São reconhecidos aos índios seus direitos sobre as terras de posse imemorial, onde se acham permanentemente localizados, sua organização social, seus usos, costumes, línguas, crenças e tradições, competindo à União a proteção desses bens. $\S 1$ O Os atos que envolvam interesses das comunidades indígenas terão a participação obrigatória de órgão federal próprio, sob pena de nulidade ${ }^{39}$ (grifo nosso)

Se conseguimos compreender bem, não deixa de ser curiosa e, até mesmo, contraditória a justificativa apresentada pelo parlamentar para a retirada da expressão "direitos originários" do texto:

Retira-se do "Caput" do Art. 268 a palavra originários, como qualificativo dos direitos dos índios com a finalidade de dar mais consistência, mais objetividade e maior segurança às populações indígenas nacionais. Direitos originários ou direitos originais, são aqueles que se transmitem, inalterados, desde a origem, para sempre, no mesmo estado, sem modificação. Ao ser um direito intrínseco e assim, transmissível, está sujeito a ser reivindicado por todo o sempre na inteireza, como era no princípio (origem), desprezando-se toda e qualquer mutação verificada, ainda que por força de leis, tenham sido editadas entre o momento do nascimento do direito (origem) até o momento de reivindicação. A manter a expressão direitos originários, eleva-se o direito do índio acima da estrutura legal da Brasil e se consagra hoje um direito, que por ser original ou originário, é anterior à própria formação do Estado Brasileiro, e portanto não alcançado, nem sujeito às suas leis. Retira-se do $\S 1^{\circ}$ a participação do Ministério Público nos atos que envolvem interesses das comunidades indígenas por já constar a participação de órgão federal próprio, com funções específicas. ${ }^{40}$

Veja-se, ainda, que na proposta do Projeto do Centrão para o § 2 ㅇ do artigo 268, desaparece a consulta às comunidades, propondo apenas que "O aproveitamento de

38 GAIGER, Julio. "Informe Constituinte”. n.o 36, p.6. Brasília: Cimi, 19. ago. 1988 (apud LACERDA, 2008. p. 125).

39 BRASIL. Assembleia Nacional Constituinte. Projeto de constituição. Emendas oferecidas em plenário. Vol 1, Brasília-DF, Disponível em https://www.camara.leg.br/internet/constituicao20anos/DocumentosAvulsos/vol-254.pdf. p. 186. Acesso em 12.02.2019.

40 Idem 
recursos hídricos, dos potenciais energéticos e a das riquezas minerais em terras indígenas, observada a legislação específica, obriga à concessão de participação no resultado em favor das comunidades indígenas, na forma da lei".

Para o § 10 do artigo 269 o Centrão sustentou que as terras em questão "são bens inalienáveis e imprescritíveis da União, cabendo a esta demarcá-las, ouvido o Senado Federal". Este coletivo de parlamentares também foi responsável por propor que, no artigo 270 (atual artigo 232), o ingresso em juízo dos indígenas estivesse obrigatoriamente vinculado à representação do Ministério Público, ofendendo a ideia do fim da tutela que vinha sendo discutida na Constituinte até então ${ }^{41}$. Quando a discussão no interior da sala da liderança do PMDB foi finalizada os parlamentares tinham acordado uma Emenda-fusão substitutiva do Capítulo "Dos índios", a qual seria votada no Plenário em dois turnos, no dia $1^{\circ}$ de junho e no dia 30 de agosto de 1988.

O texto final resultante das votações do Plenário , ou seja, os atuais artigos 231 e 232 da Constituição, passou por um longo processo legislativo que se iniciou, podemos dizer, com a prévia elaborada pelo jurista José Afonso da Silva na Comissão Afonso Arinos. Esta redação por ele proposta, embora não tenha sido encaminhada oficialmente à ANC, foi absorvida pelos parlamentares da Subcomissão de Negros, Indígenas Pessoas com Deficiência e Minorias que a tomaram como base orientadora de seus trabalhos. A redação resultante da Subcomissão atravessou debates e ataques na Comissão da Ordem Social e na de Sistematização para seguir adiante e compor-se com as importantes emendas e destaques apresentados em plenário.

Embora muitas lideranças indígenas tivessem retornado à Brasília para acompanhar a votação final, apenas Ailton Krenak, que possuía autorização especial para ingressar nas galerias do Plenário, conseguiu assistir à votação; uma demora na concessão das autorizações às demais lideranças indígenas impediu que chegassem às galerias a tempo ${ }^{42}$.

Apesar de algumas supressões de temas caros aos indígenas, como o reconhecimento do estado plurinacional e multilinguístico, a Constituição consolidou uma vitória da luta indígena pela previsão de seus direitos na nova Carta Magna. Pela

41 BRASIL. Assembleia Nacional Constituinte. Estudo comparativo, correlacionando o - Projeto de constituição (A) com as emendas do "Centrão" e as demais emendas de Plenário e com os destaques apresentados. Disponível em http://www2.camara.leg.br/atividadelegislativa/legislacao/Constituicoes_Brasileiras/constituicao-cidada/o-processoconstituinte/plenario/vol283_FaseSSIMtituloVIII.pdf Acesso em 12.02.2019.

42 Idem, p. 137. 
primeira vez inscreveu-se no texto constitucional o direito originário dos povos indígenas às suas terras e, também, a legitimidade dos indígenas e suas organizações para ingressarem em juízo. Santili afirma que a constituição de 1988 "abandona a tradição assimilacionista e encampa a ideia - a realidade dos fatos - de que os índios são sujeitos presentes e capazes de permanecer no futuro" (SANTILLI, 2000).

\section{CAPÍTULO VIII - DOS ÍNDIOS}

Art. 231. São reconhecidos aos índios sua organização social, costumes, línguas, crenças e tradições, e os direitos originários sobre as terras que tradicionalmente ocupam, competindo à União demarcá-las, proteger e fazer respeitar todos os seus bens.

$\S 1$ O São terras tradicionalmente ocupadas pelos índios as por eles habitadas em caráter permanente, as utilizadas para suas atividades produtivas, as imprescindíveis à preservação dos recursos ambientais necessários a seu bem-estar e as necessárias a sua reprodução física e cultural, segundo seus usos, costumes e tradições.

§ 2 - As terras tradicionalmente ocupadas pelos índios destinam-se a sua posse permanente, cabendo-lhes o usufruto exclusivo das riquezas do solo, dos rios e dos lagos nelas existentes.

$\S$ 3o 0 aproveitamento dos recursos hídricos, incluídos os potenciais energéticos, a pesquisa e a lavra das riquezas minerais em terras indígenas só podem ser efetivados com autorização do Congresso Nacional, ouvidas as comunidades afetadas, ficando-lhes assegurada participação nos resultados da lavra, na forma da lei.

$\S 40$ As terras de que trata este artigo são inalienáveis e indisponíveis, e os direitos sobre elas, imprescritíveis.

$\S 5$ o É vedada a remoção dos grupos indígenas de suas terras, salvo, "ad referendum" do Congresso Nacional, em caso de catástrofe ou epidemia que ponha em risco sua população, ou no interesse da soberania do País, após deliberação do Congresso Nacional, garantido, em qualquer hipótese, o retorno imediato logo que cesse o risco.

$\S 6$ São nulos e extintos, não produzindo efeitos jurídicos, os atos que tenham por objeto a ocupação, o domínio e a posse das terras a que se refere este artigo, ou a exploração das riquezas naturais do solo, dos rios e dos lagos nelas existentes, ressalvado relevante interesse público da União, segundo o que dispuser lei complementar, não gerando a nulidade e a extinção direito a indenização ou a ações contra a União, salvo, na forma da lei, quanto às benfeitorias derivadas da ocupação de boa fé.

$\S 70$ Não se aplica às terras indígenas o disposto no art. 174, § 3 으 e § 4 ㅇ․

Art. 232. Os índios, suas comunidades e organizações são partes legítimas para ingressar em juízo em defesa de seus direitos e interesses, intervindo o Ministério Público em todos os atos do processo.

\section{Considerações finais}

Muitos dispositivos dormem na constituição sem que a regulamentação tenha acontecido, diz Marcos Emílio Gomes, nos lembrando a fala do ex-deputado Ibsen 
Pinheiro:

A constituição recebeu todas as demandas da nação e deu a cada uma a resposta possível e mais democrática para aquele momento: cravando a solução quando elas podiam ser objeto de consenso ou endereçando-as para o futuro, à espera do dia em que a sociedade seja capaz de se entender quanto ao tema (GOMES, 2013, p. 156).

Procrastinar era muitas vezes a melhor saída para um impasse, disse o dep. Augusto Carvalho do $\mathrm{PCB}^{43}$. O artigo 231 parece ser um desses casos, um dispositivo até hoje inacabado. Despertado de um sono profundo na segunda metade da década de 90, passou por alguma efetivação em áreas de colonização mais recente, mas sofre, atualmente, um ataque corrosivo ao tentar efetivar-se em regiões de colonização mais consolidada. Sua rota de colisão com o avanço da fronteira agrícola reaquece insistentemente, no Legislativo e no Judiciário, os mesmos debates ocorridos há 30 anos durante o processo constituinte.

A emblemática votação, por exemplo, da Pet. $3388 / R^{44}$ em 2009, sobre a Terra Indígena Raposa Serra do Sol, trouxe para a Corte os mesmos debates ocorridos em 1987 e 1988. A imemorialidade das terras, que o Centrão tinha tentado reinserir no texto na Comissão de Sistematização e não conseguiu, reapareceu na votação da Petição. A proibição da demarcação em regiões de fronteira, debatido à exaustão na SNPIPDM, na Comissão de Ordem Social, na Comissão de Sistematização e no Plenário também ressurgiu acompanhado do tema da demarcação "em ilhas".

Do mesmo modo reaparece o tema do garimpo e do usufruto dos indígenas sobre o subsolo, tornando-se uma condicionante do Voto, para reiterar a proibição já existente no texto constitucional e para, em seguida, o Ministro Barroso, relator dos Embargos de Declaração opinar pela permissão desde que para fins de uso tradicional. A decisão mais desarmônica com o texto constitucional talvez tenha sido a tese do marco temporal na qual o relator estabeleceu nova condição a ser atribuída ao caráter de permanência da habitação dos indígenas em suas terras.

Requentar as discussões da Constituinte sobre assuntos indígenas não é fato recente. Veja-se, por exemplo, a subscrição pelo Brasil da Convenção 169 da Organização Internacional do trabalho - OIT em 1989. A Convenção em seu artigo sexto garante aos indígenas sejam consultados pelo Estado previamente sobre temas que os

\footnotetext{
43 Idem.

${ }^{44}$ BRASIL. Supremo Tribunal Federal. Petição n ${ }^{\circ}$. 3388. Ministro Relator Carlos Ayres Britto, 2009. Disponível em: <http://www.stf.jus.br/arquivo/cms/noticiaNoticiaStf/anexo/pet3388CB.pdf>. Acesso em 24.09.2015.
} 
afetem. Lembre-se que essa garantia foi retirada pela Comissão de Sistematização do anteprojeto produzido pela Comissão de Ordem Social. Já no ano seguinte à promulgação da Constituição, portanto, a assinatura da Convenção reacendia um debate da constituinte. Em 2004 a Convenção foi internalizada ao ordenamento jurídico, por meio do decreto n. 5051 ${ }^{45}$, mas em 2014 parlamentares liderados por Paulo Cesar Quartiero (DEM/RR), ensaiaram denunciar a Convenção para revogar a subscrição do Brasil (PL 1.471/2014) ${ }^{46}$ mesmo sob a desaprovação do Ministério de Relações Exteriores.

Os exemplos são muitos e não caberiam no presente artigo. Isto porque sequer abordaremos o tema da revogação tácita de dispositivos do Estatuto do Índio (Lei 6.001/73) que são flagrantemente inconstitucionais, mas que diversos magistrados insistem em utilizá-los em suas decisões. Não é nosso objetivo nesse momento exaurir com exemplos as ambivalências da legislação. Pretendemos, antes, problematizar as razões de tal ambivalência. É sabido que a legislação indigenista possui diversas lacunas e texturas abertas, mas é curioso observar que, mesmo quando clara e objetiva, ela é sempre reinterpretada, os mesmos debates insistem em aparecer para, de acordo com o momento, criar novos significados para os significantes descritos nas normativas.

Poder-se ia argumentar que é normal que isso ocorra em conformidade com as mudanças pelas quais uma sociedade passa ao longo dos tempos. O que chama atenção no caso do artigo 231, todavia, é o fato de ele estar deste a constituinte em um movimento pendular permanente e inacabado, disputado sob os mesmos debates. Não se trata de debates outros, novos, surgidos de contextos decorrentes de transformações no seio da sociedade, mas sim dos mesmos debates de há trinta anos. E com um decréscimo democrático: os debates ocorrem agora sem a presença dos indígenas e dos indigenistas que participaram da constituinte e lograram, naquele momento, inscrever garantias no texto constitucional. Estes atores, por diversas razões, não galgaram os espaços de poder que, pós constituinte, iniciaram a desconstrução desse mesmo texto. Nem, tampouco, a pauta angariou representantes suficientes no parlamento e no judiciário que impeçam a corrosão pela qual passa o dispositivo. Exemplo disso é a PEC

45 BRASIL. Decreto n. 5.051 de 19 de abril de 2004. Disponível em http://www.planalto.gov.br/ccivil_03/_ato2004-2006/2004/decreto/d5051.htm .

46 BRASIL. Câmara dos Deputados. Projeto de Lei n. 1471/2014. Disponível em: http://www.camara.gov.br/proposicoesWeb/prop_mostrarintegra?codteor=1257979\&filename=Avulso+$\mathrm{PDC}+1471 / 2014$ e http://www2.camara.leg.br/camaranoticias/noticias/AGROPECUARIA/469394COMISSAO-DEBATE-REVOGACAO-DE-CONVENCAO-DA-OIT-SOBRE-POVOS-INDIGENAS-E-TRIBAIS.html 
215 , que objetiva alterar radicalmente $\mathrm{o}$ artigo.

É relevante entender o significado da Assembleia em seu contexto políticojurídico e cotejá-lo com os acontecimentos pós-constitucionais para perceber como os atores, suas mudanças de posições, suas motivações individuais e coletivas, se conjugaram em uma decisão coletiva que se propunha final, mas se mostrou inacabada. Compreender os modos como os compromissos foram estabelecidos pode ser um indicativo da falta de efetividade dos anos que se seguiram.

O estudo do constitution-making é imprescindível para a teoria constitucional contemporânea vez que explicita elementos fundamentais para a compreensão do direito, aliás o modelo de elaboração da constituição pode vir a revelar importantes aportes à interpretação da constituição. Se os negros e as mulheres tivessem participado da assembleia constituinte americana talvez o resultado para história constitucional daquele país tivesse sido diferente, afirma Tribe e Landry (1992). Certamente não define os usos que serão feitos da Constituição nos anos seguintes, é verdade, mas tem efeitos na difícil escolha dos valores a serem constitucionalizados e no peso simbólico no texto constitucional, pois a constituição não constitui apenas a estrutura de estado, mas também agrega as pessoas em uma comunidade de princípios.

A manifestação do poder constituinte não pode ser ignorada por aqueles se propõem a interpretar a Constituição. Mais do que um poder homogêneo a experiência constituinte é permeada pelos conflitos e clivagens sociais que a integram e isso segue vivo na sociedade após o encerramento dessa experiência. As constituições são elaboradas por indivíduos, inseridos no seu contexto político, ligados ou não a travas corporativas, imersos em disputas políticas e jurídicas. Não há como o texto constitucional não refletir essas disputas. Entender o processo político-jurídico pelo qual o compromisso foi estabelecido pode nos ajudar a densificar as interpretações que vem sendo feitas acerca do texto constitucional e, quiçá, transpor uma onda cíclica de constante reinterpretação casuística do texto constitucional permeada pela influência de anseios sociais momentâneos.

Referências bibliográficas

ALCÂNTARA, Gustavo K., MAIA, Luciano M., TINÔCO, Lívia N. (Org.) Índios, direitos originários e territorialidade. Brasília: Editora ANPR, 2018. Disponível em: 
http://anpr.org.br/assets/uploads/files/publicacoes/i\%20-\%20j/indiosPDF.pdf

ANTUNES, Paulo de Bessa. A Demarcação das Terras Indígenas e a Constitucionalidade do Decreto n²2/91. Revista do Ministério Público do Rio Grande do Sul, Vol. 37, 1996.

BRASIL. Anteprojeto de Constituição - Comissão Provisória de Estudos Constitucionais. Disponível

em: https://www.camara.gov.br/internet/constituicao20anos/DocumentosAvulsos/vol219.pdf

BRASIL. Câmara dos Deputados. Projeto de Lei n. 1471/2014. Disponível em: http://www.camara.gov.br/proposicoesWeb/prop_mostrarintegra?codteor=1257979\&fi lename=Avulso+-PDC+1471/2014

BRASIL. Comissão Nacional da Verdade. Vol. II. Texto 5, p. 205. Disponível em: http://cnv.memoriasreveladas.gov.br/images/pdf/relatorio/Volume\%202\%20-

\%20Texto\%205.pdf.

BRASIL. Decreto n. 5.051 de 19 de abril de 2004. Disponível em http://www.planalto.gov.br/ccivil_03/_ato2004-2006/2004/decreto/d5051.htm .

BRASIL. Diário da Assembleia Nacional Constituinte. Disponível em: http://imagem.camara.gov.br/Imagem/d/pdf/sup53anc01mai1987. pdf\#page=179 .

BRASIL. Supremo Tribunal Federal. Petição n. 3388. Ministro Relator Carlos Ayres Britto, 2009. Disponível em: http://www.stf.jus.br/arquivo/cms/noticiaNoticiaStf/anexo/pet3388CB.pdf .

BRASIL. Supremo Tribunal Federal. STF expõe obras da mostra "Amazônia", do fotógrafo Sebastião Salgado. Disponível em: http://www.stf.jus.br/portal/cms/verNoticiaDetalhe.asp?idConteudo=370022 .

CHAUÍ, Marilena de Souza. "O Ceticismo sobre a Constituinte". In: SALINAS FORTES, Luiz Roberto \& NASCIMENTO, Milton Meira do (Orgs.). A Constituinte em Debate. São Paulo: Editora Sofia, 1987. p. $157-165$.

CITTADINO, Gisele. Pluralismo Direito e Justiça Distributiva: Elementos da Filosofia Constitucional Contemporânea. 3. ed. Rio de Janeiro: Lumen Juris, 2004

CUNHA, Manuela C.; BARBOSA, Samuel (Org.) Direitos dos Povos Indígenas em Disputa. São Paulo: Editora Unesp, 2018.

CUNHA, Manuela. Índios na Constituição. Novos estud. CEBRAP, São Paulo , v. 37, n. 3, p. 429-443, Dec. 2018 . Disponível em $<$ http://www.scielo.br/scielo.php?script=sci_arttext\&pid=S010133002018000300429\&Ing=en\&nrm=iso>. Acesso em 09 Fev. 2019.

FERNANDES, Florestan. A Constituição inacabada - vias históricas e significado político. São Paulo: Estação Liberdade, 1989. 
GOMES, Marcos Emílio (Org.). A Constituição de 1988, 25 anos: a construção da democracia \& liberdade de expressão: o Brasil antes, durante e depois da Constituinte. São Paulo: Instituto Vladimir Herzog, 2013.

KRENAK, Ailton. Para os índios, a presença nos debates da Constituinte significou a redescoberta do Brasil. [29 de julho de 2018] Entrevista concedida à Raquel Torres. Disponível em< https://outraspalavras.net/outrasaude/nos-debates-da-constituintesindios-redescobriram-o-pais/>. Acesso em 14 de fev. 2019.

KRENAK, Ailton. Para os índios, a presença nos debates da Constituinte significou a redescoberta do Brasil. [29 de julho de 2018] Entrevista concedida à Raquel Torres. Disponível em< https://outraspalavras.net/outrasaude/nos-debates-da-constituintesindios-redescobriram-o-pais/>. Acesso em 14 de fev. 2019

LACERDA, Rosane. Os povos indígenas e a Constituinte: 1987-1988. Brasília: CIMI Conselho Indigenista Missionário, 2008.

LESSA, Renato. Dilemas da Institucionalização Brasileira: os primeiros passos rumo à Constituinte. Série Estudos. n.ㅇ 46. Rio de Janeiro: IUPERJ, 1986

LOPES, Júlio Aurélio Vianna. A Carta da Democracia: o processo Constituinte da ordem pública de 1988. Rio de Janeiro: Top Books. 2008. p. 57

PILATTI, Adriano. A Constituinte de 1987-1988: Progressistas, Conservadores, Ordem Econômica e Regras do Jogo. Rio de Janeiro: Editora PUC Rio e Lumen Juris, 2008.

QUADRAT, Samanta Viz (Org). Não foi tempo perdido: os anos 80 em debate. Rio de Janeiro: 7Letras, 2014.

ROCHA, Antônio Sérgio. A genealogia da Constituinte: do autoritarismo à redemocratização. Lua Nova. Revista de Cultura e Política. Vol. 88, 2013.

SALINAS FORTES, Luiz Roberto \& NASCIMENTO, Milton Meira do (Org.). A Constituinte em Debate. Colóquio realizado de 12 a 16 de maio de 1986, por iniciativa do Departamento de Filosofia da USP. São Paulo: Editora Sofia, 1987.

SANTANA, Carolina R. Direitos territoriais indígenas: o STF contra a Constituição. In: ALCÂNTARA, Gustavo K., MAIA, Luciano M., TINÔCO, Lívia N. (Org.) Índios, direitos originários e territorialidade. Brasília: Editora ANPR, 2018, p. 451 - 479. Disponível em: http://anpr.org.br/assets/uploads/files/publicacoes/i\%20-\%20j/indiosPDF.pdf

SANTANA, Carolina Ribeiro. "Pacificando" o direito: desconstrução, perspectivismo e justiça no direito indigenista. Dissertação de Mestrado, PUC-RJ, 2010. Disponível em: http://pucrio.summon.serialssolutions.com/\#!/search?ho=t\&q=CAROLINA\%20RIBEIRO\% 20SANTANA\&I $=\mathrm{br}$

SANTILLI, Marcio. Os brasileiros e os índios. São Paulo: Editora Senac São Paulo, 2000.

TRIBE, Laurence H.; LANDRY, Thomas K. Reflections on Constitution-making. Am. UJ Int'I L. \& Pol'y, v. 8, p. 627, 1992. 
VALENTE, Rubens. Os fuzis e as flechas: história de sangue e resistência indígena na ditadura. Coleção arquivos da repressão no Brasil. 1 ed. São Paulo: Companhia das Letras, 2017.

VERSIANI, Maria Helena. Constituinte de 1987/1988: a sociedade brasileira vive a democracia. In. QUADRAT, Samanta Viz (Org). Não foi tempo perdido: os anos $80 \mathrm{em}$ debate. Rio de Janeiro: 7Letras, 2014.

Sobre os autores

\section{Carolina Ribeiro Santana}

Doutoranda no Programa de Pós-graduação em Direito UnB. E-mail: kkrsantana@gmail.com

\section{Thiago Mota Cardoso}

Doutor em Antropologia Social pela Universidade Federal de Santa Catarina, professor colaborador do Programa de Pós-Graduação em Antropologia da Universidade Federal da Bahia. E-mail: thiagotxai@gmail.com

Os autores contribuíram igualmente para a redação do artigo. 